\title{
THEORY AND PRACTICE OF STORYTELLING WITH SCRATCHJR TO DEVELOP EARLY MATHS SKILLS
}

\author{
Annarosa Serpe \\ Department of Mathematics and Computer Science, University of Calabria (Italy)
}

\begin{abstract}
This paper seeks to contribute to the debate surrounding children and digital storytelling by focusing on its application in preschool to develop early maths skills. Starting from a literature review, the paper describes a brief relevant question of how storytelling and teaching programming can be mutually supporting and outlines the educational potential of this approach. At the crossroads between the examination of some pedagogical practices, the paper shows a modality of didactic work that is relevant and practicable for conducting digital storytelling activities in the preschool.
\end{abstract}

Keywords: Digital storytelling, early math skills, preschool, ScratchJr.

\section{Introduction}

The design and implementation of digital storytelling (DST) activities in preschool are part of the broad framework of the objectives outlined by the Piano Nazionale Scuola Digitale (PNSD - National Digital School Plan) as part of the broader programme initiated by the recent law reforming the education system, "La Buona Scuola" (The Good School), Law 107/July 2015. One of the main objectives of the PNSD is to promote and support students' skills in the efficient and effective use of technologies as well as to train teachers in the use of new models of didactic interaction that involve the involvement of technologies. In this direction, the objective envisaged by action \#7 of the PNSD is to promote of the implementation of 'innovative learning environments' in the schools where technologies have an enabling but not exclusive role: a sort of 'digital carpet' in which, however, imagination and 'doing' meet, combining tradition and future through didactic practices. In this perspective of transversal learning, didactic scenarios built around computational logic and thinking, manual and digital artefacts, serious play and storytelling find their natural home. This paper is part of this perspective and focuses on digital storytelling (DST) with ScratchJr as one of the possible resources that can be used in the preschool to develop early maths skills. Indeed, DST helps the teacher implement best practices in early childhood because it integrates knowledge across domains. Overall, language is an important component of both early literacy and early numeracy, so these are two important skill areas during the early childhood period. Not only are these skills critical in and of themselves in terms of early school success, they are also necessary building blocks for knowledge in other areas. Therefore, the purpose of this paper is to recommend the use of DST practices as an educational methodology to promote maths skills and support critical use of digital technologies in the preschool.

\section{Theoretical background}

Storytelling has a very important role in developing the narrative skills that are fundamental for a child's cognitive and emotional growth. Regarding the early developments of maths skills, in particular, storytelling is a favoured tool as it guides children towards learning general notions of logical concepts and favours the acquisition of a way of thinking which will later help them to approach mathematics as a way of doing, thinking and acting. The use of the storytelling approach in instructional applications dates back to earlier time. Stories have been tools preferred by teachers as they help children understand difficult and abstract subjects. For a long time, storytelling was employed spontaneously rather than as a deliberate and planned instructional approach in early childhood education (Coskie, Trudel \& Vohs, 2010; Philips, 2013). The understanding of the use of storytelling as an engaging and meaningful teaching approach in early literacy education began with a study by Egan (1985 and 1989) highlighting that teaching is best shaped in story formats because storytelling stimulates children's imagination which is a very powerful learning tool. 
Subsequent research studies noted that storytelling can nurture cognitive engagement, critical thinking, and story sequencing (Peck, 1989; Kim, 1999, Serpe 2013; Cremin, Flewitt \& Mardell, 2017). These researches have shown also that follow-up activities such as discussion, retelling, and topic-related activities (written, drama, oral) can further enhance literacy development. Today, with the use of technology, traditional storytelling has been replaced by digital storytelling (DST). Commonly, the DST refers to the process of developing a multimodal narrative (pictures, video, sound effects, music or text), using digital tools icons (Meadows, 2003; Robin, 2008; Brígido-Corachán \& Gregori-Signes, 2014). Put simply, the DST can be understood as the practice of inventing and telling stories through a combined use of a variety of languages: verbal, visual, sound and digital. DST is used at all levels of education from early childhood to higher education. Several studies have also generated qualitative evidence that DST has beneficial effects on encoding, visual perception, creative thinking, and fine motor skills (Kocaman-Karoğlu, 2015; Sylla, Coutinho, Branco \& Muller, 2015). For children the activity of DST opens up more learning opportunities because it helps them organize and express their ideas and knowledge in a distinctive and meaningful way (Robin, 2008). It even allows children younger than six to understand a new language and to enjoy a story through digital media, without knowing how to read it.

DST can therefore facilitate a constructivist approach to teaching and learning (Sadik 2008). Research literature shows that it can be considered a useful educational tool for using digital devices to support media literacy (Maureen, van der Meij \& de Jong, 2018). In addition to building on students' technological skills, DST encourages further educational outcomes because it increases student motivation and helps teachers build constructivist learning environments that encourage creative problem-solving based on collaboration and peer-to-peer communication. Additionally, DST can be used to facilitate integrated approaches to curriculum development and engage students in higher order thinking and deep learning (Dakich 2008). Consequently, as the literature review has revealed, DST can be used for different purposes due to its benefits to the educational process. In the relevant preschool literature, it is seen that DST activities have been used to determine pre-service teachers' current states and changes they have undergone in relation to technology (e.g. Callens \& Elen, 2010; Toki \& Pange, 2014; Kildan \& Incikabi, 2015; Yuksel-Arslan, Yildirim \& Robin, 2016), in maths activities (Pramling \& Samuelsson, 2008; Inan, 2015; Preradovic, Lesin \& Boras, 2016), and in other aspects. In preschool, the DST can be used as a powerful model for creating constructivist learning environments. Indeed, based on the pedagogical theory of constructivism, children's learning is an active and social process where they should discover and construct knowledge for themselves. DST has the potential to engage children in integrated approaches to learning with digital media.

The literature indicates that children are interested in making animation using the ScratchJr digital multimedia editing tool (Bers \& Resnick, 2015; Thompson \& Tanomoto, 2016; Serpe 2019).

ScratchJr is a visual programming language (VPL) designed to introduce coding skills to children aged 5-7. It builds on the VPL Scratch (Resnick, Maloney, Monroy-Hernández, Rusk, Eastmond, Brennan, ... \& Kafai, 2009) which uses interconnecting on-screen blocks to program character animations. ScratchJr maintains the creative programming elements of Scratch, which allow children to easily create interactive short stories and games. It has a user's library of projects, a main project editor, and tools for selecting and drawing characters and background graphics. The characters can be added to a scene, and are given behaviours by combining instruction blocks. The ScratchJr interface allows children to use blocks that control motion, looks, sound, character communication, allows children to use blocks that control motion, looks, sound, character communication, and more. When children open the ScratchJr app they are prompted to create a new project, open an existing project, or explore various learning resources. In the process, children learn early maths and literacy concepts and develop valuable problem-solving skills. Scratch's constructivist matrix allows children to become protagonists of their learning. It does this precisely because they are involved in interactive and meaningful experiences rather than in passive experiences where knowledge is transmitted directly from the teacher to the children. Scratch thus allows children to play the role of problem-solver (Ferguson 2011); at the same time, it allows teachers to demonstrate to children an active use of the digital tool by linking it to knowledge of the contents, problem-solving and creative thinking. Consequently, a VPL like ScratchJr offers new ways of teaching and learning processes in preschool. The paper fits into this theoretical framework and puts forward an activity to support the integration of DST in Early Childhood Education. This activity is taken from an action-research project realised by university and school working together - targeted to design scaffolds, trough micro-modules, for children to gain content knowledge in the areas of early literacy and early maths, as specified in greater detail in the introduction. 


\section{Methodology}

Following the theoretical framework, the researcher with the teachers designed the active learning environments based on the DST with ScratchJr tool. The DST planning aims to help children see and experience how mathematical ideas interconnect and build on one another to produce a coherent whole. Consequently, the components related to each phase of the authoring process have not been neglected (tellability, the initial scenario, Storyboard, discussing the scenario with children and recapitulation, voice insert, etc.). Given the specific characteristics of the A-R project, the main pedagogical goals can be briefly summarized as follows:

- use DST for stimulating mathematical learning through the identification of interdisciplinary connections among different fields of experience;

- $\quad$ scientific control of the conditions and procedures in the use of ScratchJr to practice maths and literacy content and other cognitive skills such as creativity, critical thinking, and problem solving;

- $\quad$ strengthen the skills profile of preschool teachers in the use of digital tools.

The didactic action saw the involvement of 26 children belonging to two sections of a traditional urban Calabrian preschool that has been collaborating for years with researchers from the University of Calabria in the field of initial and in-service teacher training. The systematic documentation of the entire A-R project was the subject of a thesis in Primary Education Sciences of the University of Calabria. The methodological-didactic scaffolding was structured in full respect of the biopsychic, social and cultural peculiarities of the children as well as their learning styles and rhythms. It is based on a series of concrete learning experiences - posed on individual, group and direct instruction by the teacher - exploiting various recurring moments of everyday life. Consequently, the educational-training paradigm followed was to carry out activities related to ideas and concepts first in a traditional way (without the use of technology) and then with a tablet, using the ScratchJr app based on the context and the didactic intentionality.

\subsection{DST with ScratchJr: Theater of numbers}

Number concepts become significant to children when they develop out of experiences that are functional in the world of those children. Here, below, we show a DST activity extrapolated from the micro-module 'Number sense' aimed at linking many types/quantities of concrete objects and actions to numbers. Specifically, the activity goals focused on:

$\circ$ the control of visual-motor coordination and fine motor skills;

○ to count accurately - first forward from 0 to 10 , then to count backwards;

o identify the positions of objects and people in space, using terms such as forward/back, up/down, right/left;

o experimenting with different and multidirectional languages through dramatization (traditional and digital).

On this basis, the activity with children was organized as follows: (1) the telling of a short story of numbers (zero to ten) to the children by the teacher; (2) conversation with the children (prompt questions); (3) transition from mental images to practice through different approaches which employ different and multidirectional languages; (4) reflection on the practical activities; (5) iconic, ideographic and graphic-symbolic representation; (6) theatre approach on combining hands-on activities with Scratch Jr and more traditional tools. For reason of space, only some extracts relating to the above-mentioned phases will be included. Fig. 1 shows a sequence of the traditional dramatization activity: the theatre with number-shaped puppets (made by children), the animation of the number 3 (the child animates the number puppet by saying/reciting 'I come after two and I'm three, no one is as perfect as me') and the animation of subsequent numbers.

Figure 1. Theatre of numbers - Traditional dramatization by children.
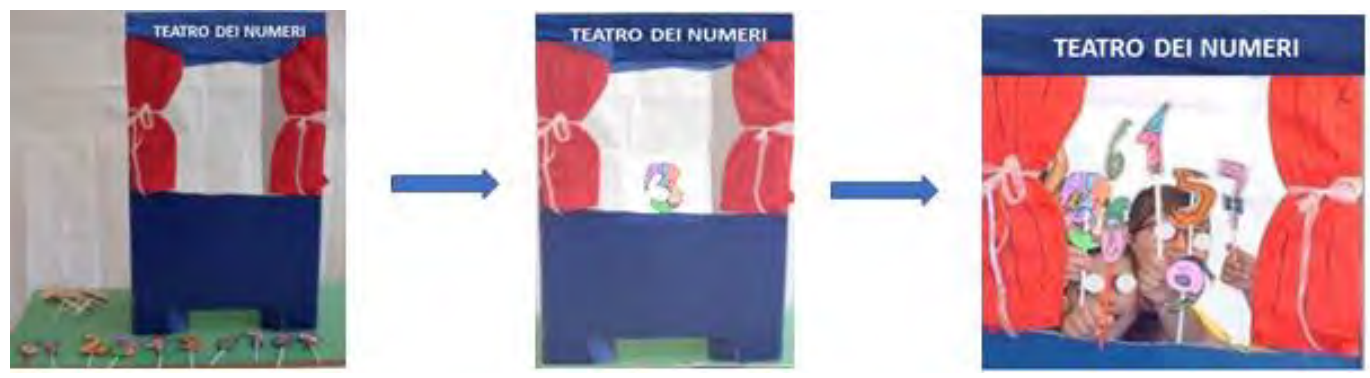

The theatre approach supports the children in the development of their narrative skills, not only with reference to the chronological sequence of narrative events, but also with the exploration of a child's own creative and expressive, personal and emotional, social dimension. Moreover, the theatre approach enables children to have full control of the story. 
At this point, the generalizations and the switch to greater levels of abstraction are aided by a tablet with the ScratchJr App enabled. Specifically, the children must create a project based on a real experience; in other words, it is a matter of representing stages related to the "Theatre of numbers" (Figure 2). Consequently, the elements of ScratchJr that must be brought into play when one thinks of a program as the result of a process of logical organization and structuring and as a means of communication are discussed. In this activity, the children are no longer able to act with their whole body because the perceptive-visual channel and the use of hand-eye coordination are mainly used. They have to invent a series of instructions in sequence to reach the goal (Serpe 2019).

Figure 2. ScratchJr project "Theatre of numbers".
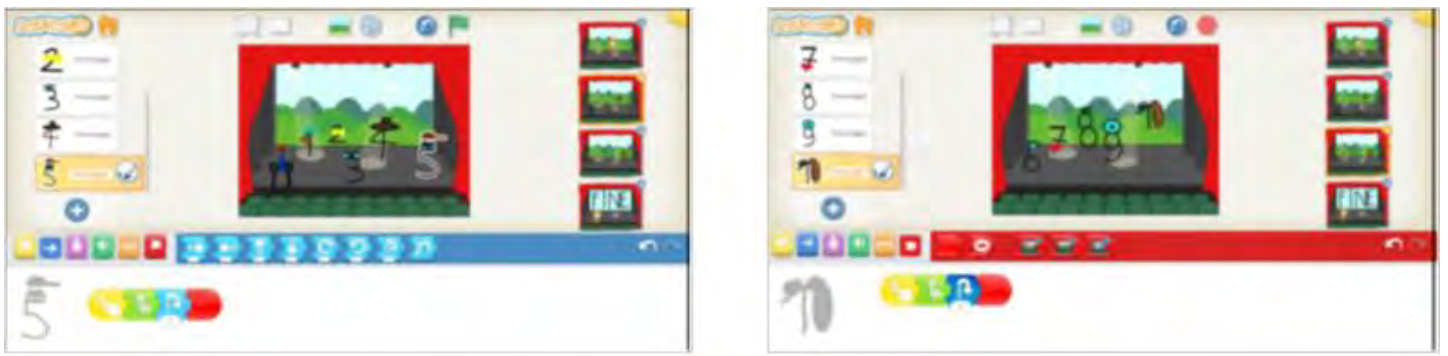

Working with ScratchJr is like working in a theatre where the action takes place on a stage where the sprites perform a script. In this way, the children have written their story without writing a single line of code and without knowing programming: simply by moving blocks to create sequences of behaviour of the individual characters. The children tell their story - Theatre of numbers- by creating a concatenation of coloured blocks that represent the elementary steps, or the instructions that describe them. Specifically, they have utilized the following blocks: Sound (green), Motion (blue), Triggering (yellow), and End (red).

\section{Assessment}

For the evaluation phase, an observation protocol was drawn up which stated the expected levels of competence, the indicators for checking and the achieved objective. This protocol was used by the teachers while the children were carrying out the activities. The choice was dictated by the need to obtain reliable results which were not influenced by possible expectations, rather than the somewhat confused recollections of the chidren's individual responses recorded at a later stage, as well as by the need to keep options open to unexpected behavior triggered by DST in the classroom. A qualitative rather than a quantitative reading brought to the fore the range of individual responses to the single classroom initiatives, in an effort to find the children's reaction to each suggested activity.

\section{Conclusion}

DST is a new pedagogical approach that has the potential to induce a basic shift in the learning process because it helps the children not only to read technology but turns them to active protagonists. The VPL ScratchJr is a tool very easy tool to use to create games, simulations, animated stories, maths experiments and animated presentations. It's fun to use because the children can work on digital literacy skills tailored to their developmental level, such as understanding and utilizing digital interfaces, non-linear navigation, critical thinking, problem-solving, cooperative learning, creative design and many others. Ultimately, DST assessment using ScratchJr makes children think creatively and it enhances their design skills, and, last but not least, allows children to start develop 21 st century skills.

\section{References}

Bers, M.U., \& Resnick, M. (2015). The official ScratchJr book: Help your kids learn to code. No Starch Press.

Brígido-Corachán, A.M., \& Gregori-Signes, C. (2014). Digital storytelling and its expansion across educational context. In A. M. Brígido-Corachán \& C. Gregori-Signes (Eds.), Appraising digital storytelling across educational contexts (pp. 13-29). Valéncia: Universitat de Valéncia.

Callens, J.C., \& Elen, J. (2010, May). Digital storytelling as a mediation tool to support in-depth reflection? In Global Learn (pp. 790-795). Association for the Advancement of Computing in Education (AACE). 
Coskie, T., Trudel, H., \& Vohs, R. (2010). Creating community through storytelling. Talking Points, 22(1), 2-9.

Cremin, T, Flewitt, R, \& Mardell, B. (Eds) (2017) Storytelling in Early Childhood: Language, Literacy, and Culture. London and New York: Routledge.

Dakich, E. (2014). Theoretical and Epistemological Foundations of Integrating Digital Technologies in Education in the Second Half of the 20 th Century. In Reflections on the History of Computers in Education (pp. 150-163). Springer, Berlin, Heidelberg.

Egan, K. (1985) Teaching as Story-telling: A Non-mechanistic Approach to Planning Teaching. Journal of Curriculum Studies, 17:4, 397-406.

Egan, K. (1989). Teaching as story telling: An alternative approach to teaching and curriculum in the elementary school. University of Chicago Press: Chicago.

Ferguson, D. (2001). Technology in a constructivist classroom. Information Technology in Childhood Education Annual, 2001(1), 45-55.

Inan, C. (2015). A Digital Storytelling Study Project on Mathematics Course with Preschool Pre-Service Teachers. Educational Research and Reviews 10 (10):1476-1479. doi:10.5897/ERR2015.2247.

Kildan, A. O., \& Incikabi, L. (2015). Effects on the technological pedagogical content knowledge of early childhood teacher candidates using digital storytelling to teach mathematics. Education 3-13, 43(3), 238-248.

Kim, S. Y. (1999). The Effects of Pretend Play and Storytelling upon Narrative Recall. Korean Journal of Child Studies, 20(2), 205-223.

Kocaman-Karoğlu, A. (2015). The changing nature of storytelling by means of technology in the instructional process: Digital storytelling. Educational Technology Theory and Practice, 5(2), 89-106.

Maureen, I. Y., van der Meij, H., \& de Jong, T. (2018). Supporting literacy and digital literacy development in early childhood education using storytelling activities. International Journal of Early Childhood, 50(3), 371-389.

Meadows, D. (2003). Digital storytelling: Research-based practice in new media. Visual Communication, 2(2), 189-193.

Peck, J. (1989). Using storytelling to promote language and literacy development. The Reading Teacher, 43(2), 138-141.

Phillips, L. (2013). Storytelling as pedagogy. Literacy Learning: The Middle Years, 21(2), ii.

Pramling, N., \& Samuelsson, I.P. (2008). Identifying and solving problems: Making sense of basic mathematics through storytelling in the preschool class. International Journal of Early Childhood, 40(1), 65-79.

Preradovic, N.M., Lesin, G.\& Boras D. (2016). Introduction of Digital Storytelling in Preschool Education: A Case Study from Croatia. Digital Education Review 30: 94-105.

Resnick, M., Maloney, J., Monroy-Hernández, A., Rusk, N., Eastmond, E., Brennan, K., ... \& Kafai, Y. (2009). Scratch: programming for all. Communications of the ACM, 52(11), 60-67. Retrieved from https://dl.acm.org/doi/fullHtml/10.1145/1592761.1592779 e

Robin, B. R. (2008). Digital storytelling: A powerful technology tool for the 21 st century classroom. Theory into Practice, 47(3), 220-228.

Sadik, A. (2008). Digital storytelling: A meaningful technology-integrated approach for engaged student learning. Educational Technology Research and Development, 56(4), 487-506.

Serpe, A. (2013). 'Doing Mathematics' in The Nursery School: I'll Tell You a Story. In L. Gómez Chova, A. López Martínez \& I. Candel Torres (Eds), ICERI2013 Proceedings (pp. 883-891). Valencia: IATED Academy.

Serpe, A. (2019) Programming with ScratchJr to create interactive Maths-Experiences in Preschool. In L. Gómez Chova, A. López Martínez \& I. Candel Torres (Eds), INTED2019 Proceedings, (2007-2016). Valencia: IATED Academy.

Sylla C., Coutinho C., Branco P., \& Muller W. (2015). Investigating the use of digital manipulatives for storytelling in pre-school. International Journal of Child-Computer Interaction, 6, 39-48

Thompson, R., \& Tanomoto, S. (2016). Children's Storytelling and Coding: Literature Review and Future Potential. In PPIG (p. 6).

Toki, E. I. \& Pange J. (2014). ICT Use in Early Childhood Education: Storytelling. Tiltai 66 (1): $183-192$.

Yuksel-Arslan, P., Yildirim, S., \& Robin, B. R. (2016). A phenomenological study: Teachers' experiences of using digital storytelling in early childhood education. Educational Studies, 42(5), 427-445. 